\title{
Digital Resources: New Management Object
}

\author{
Pozharitskaya I.M.* \\ V. I. Vernadsky Crimean Federal University \\ Simferopol, Russia \\ e-mail: iryna1106@rambler.ru
}

\author{
Klimenko O.P. \\ Sevastopol State University \\ Sevastopol, Russia \\ e-mail: klimenko.ksu@mail.ru
}

\begin{abstract}
Digitalization and transformation of business processes inevitably leads to the development of management methodology under the influence of digital technologies. Resource management of business entity requires a review of both its classification and tools. The subject of research is digital resources in terms of both economic and management theory. In the research, the following results were achieved: own definition of digital resources is formulated as a management object in digital economy; types of digital resources are distinguished based on the classification of economic benefits; characteristics of certain digital resources types are presented with the aim of ranking them according to the priority of use in digital economy; property identification is carried out for the purpose of digital resource management. The research methodology is based on using content analysis and discourse analysis of the research results published in international databases in accordance with the subject area. The suggested classification of digital resources allows further development of organizational model for digital resources management of business subject. The highlighted features of digital resources will certainly contribute to their effective management. At the same time, it is possible to use both a single digital platform and transform a business model taking into account the type of activity. In the conclusion of article further research areas are identified in part of methodological, theoretical and organizational rationale for digital resource management.
\end{abstract}

Keywords - digital resources, digital management, digital economy, digital capital, digital assets, digital workforce, digital entrepreneurship.

\section{INTRODUCTION}

The computer technology development and the digitalization of the economy require new approaches to management, both at the business entity level and at macro level. Rapid changes in practice do not allow reengineering business processes to the full extent, and especially theoretical rationale of new process management systems [1,2].

Thus, the implementation of development program for digital economy in Russia implies digital resources applying. However, the question arises: what is meant by this concept and what types of digital resources should be identified to manage them.

Complex of natural (effortless) and artificial (man-made) goods are resources that can be applied by a person, enterprise or society.

A number of authors have already investigated the transformation essence of management tools in digital economy [3, 4]. However, there was a need for a deeper research of digital resources, in particular, building an organizational structure model of digital resource management.

The purpose of the research is to develop an approach to the definition of the "digital resource" in terms of management and opportunities of developing new management methods needed in a digital economy.

As a result, the following tasks were solved:

- types of digital resources are distinguished based on the generally known classification of economic benefits;

- characteristics of certain digital resources types are presented with the aim of ranking them according to the priority of use in digital economy;

- property identification is carried out for the purpose of digital resource management.

The research methodology is based on using content analysis and discourse analysis of the research results published in international databases in accordance with the subject area.

\section{LITERATURE REVIEW}

Research of more than 800 publications (reviews, investigation and news articles, book chapters) from international databases on digital resources led to a number of conclusions. Thus, the conducted content analysis for the search words "digital resources" indicates that for 2015-2019, this term is missing in the information technology dictionaries. "Digitalization" and "digital business transformation," according to the glossary editor, should lead to the creation of new reliable business processes using digital technologies [5].

Term "digital resources" is widely used in librarianship in the last decade. Thus, electronic (digital) resources containing text or graphic information are allocated in electronic form on digital media in library resources [6]. Although this process, in fact, is the digitization of information from paper.

"Digital educational resource" has become the second direction of term application. It replaced the "electronic educational resource". Generally, digital resource is considered as educational one, which is an interactive multimedia product aimed at achieving a didactic goal or solving certain educational problems [7]. At the same time, the main difference between the electronic educational resource and the digital one is its interactive nature of application.

The third area of content analysis was textbooks and manuals, where digital resources were mentioned. Thus, in the "Classification of Digital Resources" section of the book 
"Classification in Theory and Practice" revealed how classification theories can be used in the information environment [8]. However here we are talking about library digital resources and their search in the context of information management in Internet.

Thus, we can conclude that from the viewpoint of digital economy, the use of digital resources in the scientific literature is not disclosed.

Speaking about the resources as the main object of management, we cannot but admit land, capital, labor, knowledge and entrepreneurship in economic theory. However, in conditions of the digital technologies application, these factors are transformed, changing part of their characteristics. Thus, in particular, land - as the main production factor in the 20th century, completely fades into the background in the context of digitalization. Virtual workplace, digital platforms come out on top instead of tangible assets and property complexes. Certainly, the use of natural resources is indispensable in the digital economy. But the other production factors: capital, labor, knowledge and entrepreneurship are transformed in the course of digitalization and require new management approaches.

\section{RESULTS}

Based on the foregoing, one can formulate the definition, where digital resources in the general economic sense should be understood as not just an electronic form of information, but a set of production factors (capital, labor, knowledge, entrepreneurship) reproduced in the digital economy.

Nowadays the concept of digital capital is taking the form of digital competencies (information, communications, security, content creation, etc.) and digital technology [9]. At the same time, scientists consider the relationship of digital capital with social capital, political, cultural and economic, their transformation and transition from one form to another. However, digital and informational capital should not be confused: informational one is understood as the capital of knowledge.

The second approach (accounting) involves the allocation of digital assets as an element of digital resources. New forms of resources being created in the digital environment that do not have an analogue of classical types of balance sheet assets require the restructuring of the accounting and management accounting system [10]. The intangible nature of the cryptocurrencies created in the blockchain system is a vivid confirmation of this. Legislation in the field of digital financial assets and tokens as an analogue of stocks in digital form would open up great opportunities for investment management in a digital economy. Author has already conducted research of essence and main types of digital accounting, digital financial assets accounting [11]. All this indicates the need to build a new model of digital asset management as an element of digital resources.

Digital workforce. They include a wide range of new relationships in the field of human capital: from training in digital competencies to a digital workplace, electronic workbook, etc. [12]. The Russian Federation Program in the field of the digital economy contains a large section on training and restructuring the education system. In particular, it is necessary to test and implement Internet services for citizens to self-assess their competencies in the digital economy, including free ones for assessing basic competencies; development of additional educational programs to provide "digital literacy" of the older generation; formation of a state system of incentive payments (individual digital voucher from the state) for teaching children and adults the competencies of the digital economy; introduction of intangible benefits system for employees, etc. All this makes the management to apply new human resource management practices in digitalization condition.

Digital knowledge. As the main resource of the $21 \mathrm{st}$ century, it acts as a digital economy locomotive. If in past centuries natural resources, land, fixed capital and material resources were the main engines of the economy (capitalist or market), now intangible intellectual resources (innovative technologies, information, databases, the Internet) make countries scarcely endowed with natural resources fastgrowing economies Therefore, in our opinion, this particular resource should be put in first place in the system of digital resources types.

In international databases publications the term "digital knowledge" is not fixed. Quite a lot of research articles are published in various fields of knowledge (cultural, medical, accounting, forensic, etc.) using digital technologies. That is why, to shed light on this resource scientists will require more than one decade due to its inexhaustibility.

Digital Entrepreneurship. It includes not only business processes digitization, but also the fundamental reengineering. Practical activities of electronic business not only reduce decision-making time and reduce costs, but also create new needs for management models, network interactions, digital transformation of both individual stages of activity (online orders, information delivery, etc.), and digital platforms business.

Despite the widespread Internet businesses and the emergence of new business models, little attention is paid to such developments in the scientific literature. Some topics just recently become to be affected: digitization, digitalization, digital transformation [13]. For example, marketers focused on digital advertising. Strategic management researchers focus on the conceptualization of digital business models. The literature on information systems pays attention to the development and implementation of digital technologies and platforms. At the same time, the digital transformation of the economy occurs when borders are erased and it is interdisciplinary. [14].

It is the above characteristics that allow separating elements of digital resources into separate categories, which are systematized in the form of Figure 01 .

Let us investigate the properties of digital resources by analogy with the properties of the economic resources that will determine the methodological approaches to management toolbox.

The main property of economic resources (land, capital, labor, entrepreneurship and knowledge) is their limited nature. Management should constantly make decisions about the 
appropriateness of limited resources leverage to achieve maximum results. Classical economic literature deals with opportunity costs and alternative choices. This property is uncharacteristic for digital resources, which are mainly intangible. Vice versa, the main property of such resources as mobility can be reported. Digital resources are made limitless and practically inexhaustible precisely due to mobility and the ability to instantly move and spread in space.

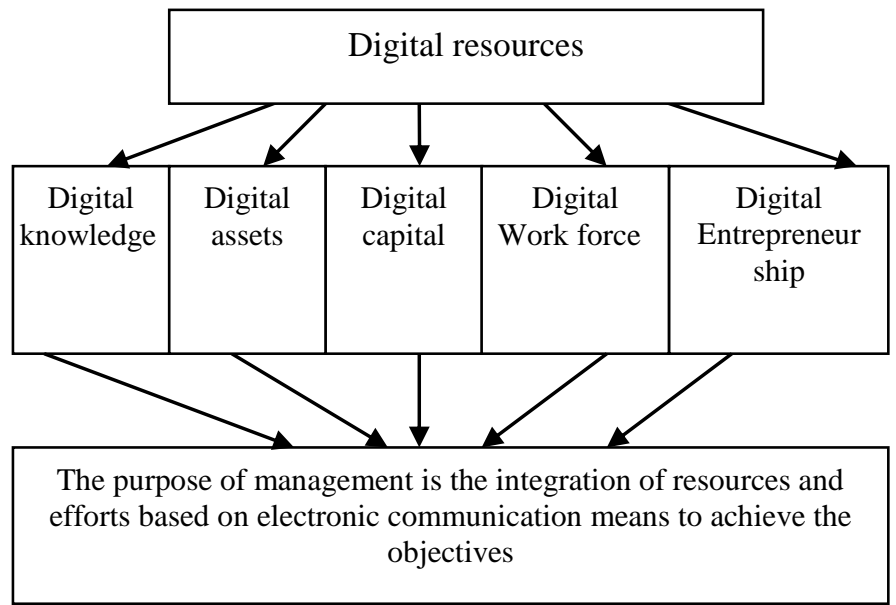

Fig. 1. Digital Resources as a Management Object

The next property of resources is their interconnectedness and interchangeability. In the classical interpretation, the applying of entrepreneurial abilities and knowledge resources in a market economy optimizes and minimizes use of natural, labor and material resources. At the same time, an increase in production due to rising costs for only one resource has a breaking point (technology - people, capital - labor, capital knowledge).

However, in the digital economy, a new characteristic feature of both digital business and digital resources is their socialization. First of all, this is the use of social networks to build new business models. Secondly, this is the creation of demand among consumers and its satisfaction, i.e. economic transformation and focus on the social needs of the population, and not just economic needs.

The third property inherent only in digital resources is the possibility of their use only with appropriate high-tech equipment (computers, servers, gadgets, etc.). Digital resources themselves are useless if there is no energy resources, as well as mobile or satellite communications and IT equipment. For example, the production of digital money cryptocurrency mining may stop if a powerful computer fails or electricity is simply cut off.

The fourth property, again specific only to digital resources, may be their vulnerability to cyber threats. It is digital (informational) security that is an integral element of a digital resource management system, starting from installing licensed operating systems and software, to anti-virus protection of cloud technologies, etc.

\section{DISCUSSION}

According to some scientists, the digital economy and business models transformation of companies requires access, acquisition or development of new digital resources. In particular, the elements of such a transformation include: digital assets, the flexibility of digital technology, the capabilities of digital networks and the ability to analyze big data [9].

Thus, the company's digital assets include data storage, communication and information infrastructure, the latest machine intelligence technologies, etc. According to several authors digital flexibility is necessary as a management tool to respond to increased competition. In addition, changing customer needs and the introduction of new digital technologies require an organizational roles diversion.

Applying digital networks capabilities involves the joint use of digital platforms with partners (Instagram, Twitter, etc.). The company management has to double (triple) the number of contacts and, accordingly, digital resources in order to satisfy the needs of customers in modern trends. In this case, three options for management activities may be distinguished:

1) activity-oriented digitalization when a digital resource optimizes existing activities;

2) resource-oriented digitalization, when a digital resource is aimed at creating new activities;

3 ) customer-oriented digitalization when a digital resource supports new customer relationships [15].

The possibilities of using Big Data analysis are also a digital resource in some way. Thus, directly digital firms Amazon and Booking.com constantly use analytics to manage service offerings and pricing for customers. Moreover, after the capabilities of big data analysis are built-in, there is a need to introduce digital competency programs to improve management methods.

The use of digital platforms is also crucial in terms of providing digital resources at the meso and macro levels The need to solve economic problems requires the creation of a single model on the issue of consolidating the production and digital resources of economic agents at the regional and federal levels [16].

The foregoing information leads to the need to develop new approaches to digital resource management to ensure the competitive advantages of business entities. And in order to provide management with tools for digital transformation, it is necessary to change the internal organizational structure of the company. That means that the use of digital resources requires a qualitatively new level of management.

\section{CONCLUSION}

It is necessary to consider the following key points in the process of digital resources researching:

- digital knowledge, digital assets, digital capital, digital workforce and digital entrepreneurship make up a single digital resource system of an economic agent; 
- the main properties of digital resources are mobility, socialization, dependence on high-tech equipment and technologies, vulnerability to cyber threats;

- the digital resources allocation as a management object depends on the tasks assigned to management based on the type of business model digitalization.

The presented approach to the digital resources allocation in the modern digital economy is indisputably subject to further research and theoretical justification. Certainly, new forms of digital resource implementation may arise that require additional elaboration.

Thus, having identified the essence and main types of digital resources, we can distinguish areas for further research:

1. Methodological rationale for the conceptual model of digital resource management.

2. Theoretical substantiation of the features of digital resources management techniques for various entities.

3. Organizational aspects of the development of techniques and procedures for managing digital resources, including attracting modern digital management tools.

\section{References}

[1] T. Sabetova, M. Ponomarenko, "Analysis and ranging of the factors of formation and development of innovative behaviour in organizations", Proc. of the Voronezh State Univer. of Engineer. Technol., vol. 80, no. 3, pp. 478-488, 2018. Retrieved from: https://doi.org/10.20914/2310-1202-2018-3-478-488

[2] I. Arenkov, S. Smirnov, D. Sharafutdinov, D. Yaburova, "Transformation of the enterprise management system in the transition to the digital economy”, Ross. predprinimatelstvo, vol. 19, no. 5, pp. 1711-1722, 2018. Retrieved from: https://doi: 10.18334/rp.19.5.39115

[3] V. Yachmeneva, A. Veretyokhin, N. Tsarenko, "Improving development management of knowledge-intensive production under the new industrialization", Advan. in Soc. Sci., Ed. and Human. Res., vol. 240, pp. 461-465, 2019. Retrieved from: https://doi: 10.2991/sicni18.2019 .93

[4] V. Reutov, D. Burkaltseva, V. Yachmeneva, M. Algina, E. Smirnova, A. Tyulin, "Features of socio-economic systems' transformation processes management", Amazonia Investiga, vol. 8, no. 22, pp. 467-474, 2019. Retrieved from: https://apps.webofknowledge.com/full_record. do?product $=$ WOS \& search_mode=GeneralSearch\&qid $=2 \&$ $\mathrm{SID}=\mathrm{F} 18$ Sva3dcMf1a2az4bC\&page $=1 \&$ doc $=1$.

[5] M. Kohtamäki, V. Parida, P. Oghazi, H. Gebauer, T. Baines, "Digital servitization business models in ecosystems: A theory of the firm", J. of Busin. Res., vol. 104, pp. 380-392, 2019. Retrieved from: https://doi.org/10.1016/j.jbusres.2019.06.027

[6] Usha Mujoo-Munshi, "Building Digital Resoucers: Creating Facilities at INSA”, The Int. Inform. \& Library Rev., vol. 35, iss. 2-4, pp. 281-309, 2003. Retrieved from: https://doi.org/10.1016/S1057-2317(03)00014-6

[7] Kui Xie, Gennaro Di Tosto, Sheng-Bo Chen, Vanessa W. Vongkulluksn, "A systematic review of design and technology components of educational Digital Resoucers", Comput. \& Ed., Vol. 127, pp. 90-106, 2018. Retrieved from: https://doi.org/10.1016/j.compedu.2018.08.011

[8] No authors, Classification in Theory and Practice. 2014, 286 p. https://doi.org/10.1016/ C2014-0-00625-9

[9] M. Ragnedda, "Conceptualizing digital capital", Telematics and Inform. vol. 35, iss. 8, pp. 2366-2375, 2018. Retrieved from: https://doi.org/10.1016/j.tele.2018.10.006

[10] D.-R. Knudsen, "Elusive boundaries, power relations, and knowledge production: A systematic review of the literature on digitalization in accounting”, Int. J. of Account. Inform. Syst., pp. 1-22, December 2019. Retrieved from: https://doi.org/10.1016/j.accinf.2019.100441

[11] I. Pozharitskaya, "Problems of Idenfication and Recording of Digital Finance Assets in Accounting", Account., Anal., Audit., vol. 5, no. 6 , pp. 61-66, 2018. Retrieved from: https://doi.org/ 10.26794/2408-93032018-5-6-61-66

[12] Y. Salikov, I. Logunova, I. Kablashova, "Trends in human resource management in the digital economy", Proc. of the Voronezh State Univer. of Engineer. Technol., vol. 81, no. 2, pp. 93-399, 2019. Retrieved from: https://doi.org/10.20914/2310-1202-2019-2-393-399

[13] G. Alia, A. Margherita, G. Passiante, "Digital entrepreneurship ecosystem: How digital technologies and collective intelligence are reshaping the entrepreneurial proce", Technol. Forecast. and Soc Change, vol. 150, pp. 3-15, 2019. Retrieved from: https://doi.org/10.1016/j.techfore.2019.119791

[14] P. Verhoef, T. Broekhuizen, Y. Bart, A. Bhattacharya, J. Dong, N. Fabian, M. Haenlein, "Digital transformation: A multidisciplinary reflection and research agenda", J. of Busin. Res., iss. 2, pp. 1-13, November 2019. Retrieved from: https://doi.org/10.1016/j.jbusres. 2019.09.022

[15] M. Pagani, C. Pardo, "The impact of digital technology on relationships in a business network", Industrial Marcet. Manag., vol. 67, pp. 185-197, 2017. Retrieved from: https://doi.org/10.1016/j.indmarman.2017.08.009

[16] A. Zatsarinnyy, A. Shabanov, "Model of a Prospective Digital Platform to Consolidate the resoucers of Economic Activity in the Digital Economy", Proc. Computer Sci., vol. 15, pp. 552-557, 2019. Retrieved from: https://doi.org/10.1016/j.procs.2019.02.092 